\title{
Nuevas aportaciones a las religiones primitivas de Hispania
}

\author{
J. M. BLÁZQUEZ MARTÍNEZ \\ M. P. Garcla-Gelabert Pérez
}

Con este trabajo ${ }^{1}$ queremos rendir justo homenaje al profesor $\mathrm{E}$. Ripoll, uno de los mayores prehistoriadores de la España actual.

1. Fernando de Almeida ${ }^{2}$ ha dado a conocer un santuario campestre romano, situado en Miróbiga dos Celticos (Portugal). El santuario es de época romana, pero suponemos la hipótesis de que se trata de un santuario romano consagrado a una deidad lusitana, equivalente al Esculapio griego, como parece desprenderse de la inscripción hallada, que dice: Aesculapio / Deo / C. Atticus Januarius / Medicus

1 J. M. BLAZZUEZ: “Últimas aportaciones a las religiones primitivas de Hispania», Homenaje a Antonio Tovar, Madrid, 1972, 81 ss. Id. “Nuevos teónimos hispánicos (Addenda y Corrigenda)", CEG 29, 1974-75, 23 ss. Id. "Últimas aportaciones a las religiones primitivas de Hispania", Estudios dedicados a Carlos Callejo Serrano, Cáceres, 1979, 1. Ss. de la separata. Id. Imagen y mito. Estudios sobre religiones mediterráneas e ibéricas, Madrid, 1977. Id. Diccionario de las religiones prerromanas de Hispania, Madrid, 1975. Id. Religiones primitivas de Hispania. I. Fuentes literarias y epigráficas, Madrid, 1962. Id. "Die Mythologie der Althispanier", Wörterbuch der Mythologie, Götter und Mythen im Alten Europa, Stuttgart, 1973, 705 ss. Id. Historia de España. España Romana, Madrid, 1982, 261 ss. Id. "Recientes aportaciones a las religiones primitivas de Hispania (Addenda y Corrigenda)", ATHLON. Satura Grammatica in honorem Francisci R. Adrados II, Madrid, 1987, 69 ss. Id. "Nuevos teónimos hispanos (Addenda et Corrigenda)", CHA 13-14, Homenaje al Prof. Gratimiano Nieto II, 1986-1987, 141 ss. Id. «Einheimische Religionen Hispaniens in der römischen Kaiserzeit", ANRW II, 1986, 164 ss. Id. Primitivas religiones ibéricas II. Religiones prerromanas, Madrid, 1989. A estos trabajos hay que añadir los del prof. J. d'Encarnação y otros investigadores lusitanos sobre religiones de Portugal, citados en estas obras.

2 "Breve noticia sobre o santuario campestre romano de Miróbriga dos Celticos (Portugal)", Homenaje a García y Bellido V, 19 ss. 
Pacensis / testamento legavit / ob merita splendi / dissimi Ordinis / [9]uod ei Quinquatri / um praestiterit / [F]abius Isas / f(aciendum).

La presencia de "deo", como ya indicó S. Lambrino ${ }^{3}$ hace años, significaría que se trata de una deidad indigena identificada con Esculapio. Precisamente "deo» acompaña frecuentemente a deidades indígenas asimiladas a otras del panteón grecorromano. Baste recordar sólo estos ejemplos publicados por A. Rodríguez Colmenero ${ }^{4}$ : I(ovi) $\mathrm{O}$ (ptimo) M(aximo)/Rivo/febo(que) D(eo), de Vila Real (Portugal); Larocu(o) d(eo) Ama Pilili Filia Libe(ns)/animo Vo/tum retuli[t] pro marito suo, de Castelo de Monforte. Chaves ${ }^{5}$ Larouc/o D(eo). Max(imo). Ped(ronio). Max/imo V(otum) / Lib(ens) A(nimo) S(olvit), del Puerto de Peña Escrita, Vilar de Perdices (Montalegre) ${ }^{6}$, etc. Una tesis muy significativa y probablemente cierta sobre el particular, defiende $\mathrm{J}$. d'Encarnacão ${ }^{7}$, según la cual cuando aparece sólo la palabra deus o deo se trata del dios de un santuario o de la región.

2. T. Ortego y Frías $^{8}$ ha publicado un conjunto de inscripciones del territorio arévaco-pelendón, del más alto interés, pues debajo de la epigrafía hay figurados bóvidos.

A) En la estela de Valloria (Soria) (fig. 1) dedicada por la madre Antonia Montana se representa una vaca que amamanta a un ternero. Ya T. Ortego, al publicar esta original inscripción, relacionaba este bóvido con ideas de ultratumba. En la parte superior hay un objeto que parece un caldero invertido. T. Ortego lo interpreta, lo que es muy probable, como una síntesis interpretativa del joven difunto. La inscripción dice así, según la lectura de T. Ortego:

Șem(pronius). Fla(vus). $F[1]-/$ [a(vi)]. f(ilius). ân(norum). XXV / h(ic). s(epultus). e(st). Ant( $\longrightarrow$ ) / Mon(tana). matt(er) / pârentátês/ $\mathfrak{t}$ (itulum) $\mathfrak{f}$ (aciendum). $c$ (uraverunt) ${ }^{9}$.

\footnotetext{
3 “Les cultes indigènes en Espagne sous Trajan et Hadrien». Les empereurs romains d'Espagne, Paris, 1965, 226.

"Un importante grupo de nuevos teónimos galaicos". Studia paleo-hispánica. Actas del IV Coloquio sobre lenguas y culturas paleo-hispánicas (Veleia 2-3), 1987, 328, núm. 1.

${ }^{5}$ A. Rodriguez Colmenero, Aquae Flaviae, Chaves, 1987, 188 ss. núm. 109.

6 A. Rodriguez Colmenero, Aquae Flaviae, 190, s. núm. 110.

7 "Divinidades indígenas peninsulares: problemas metodológicos do seu estudo", Estudio sobre la Tabula Siarensis, Madrid, 1988, 261 ss.

8 «Estelas funerarias inéditas, con representaciones bovinas en territorio arévaco-pelendón", Hoınenaje a Garcia y Bellido V, 338 ss. fig. 1.

${ }^{9}$ T. ORtego, op. cit., 330 ss. fig. 1.
} 
B) En la estela conservada en el umbral de la ermita de Vizmanos, el toro, de pie y parado, se encuentra en la parte inferior (figs. 2 y 3). Un gran círculo con cuello decora la cabecera. La inscripción dice:

[A]ṇtestia / [Se]rana / [..]eni fil(ia) / [a]n(no) I h(ic) s(epulta e(st) ${ }^{10}$.

C) La estela de Vellosillo va decorada en la parte superior con tres círculos (fig. 4). El central es de menor tamaño. La parte inferior lleva dos bóvidos, de pie, afrontados y parados, mirando, al igual que su congénere de la estela de Valloria, al espectador. La inscripción dice:

Q(uintus) Ant[o]—/nius Se[ra]—/nus a[n(norum)] / LXX hic [se]-/pultus [est] / curavit [sib]— / i f(aciendum) ${ }^{11}$.

D) El epígrafe de Yanguas dice.../lulius / Gemelus/annoru(m)/ XXXXV. El toro de pie y parado, como en las estelas anteriores, decora la parte inferior ${ }^{12}$ (fig. 5).

E) La estela de El Collado va decorada con un círculo sobre raya, que probablemente es una estilizada representación humana. La lectura es la siguiente:

$$
\begin{gathered}
\text { D(is) [M(anibus)] / QVE( ) AR [ ] / THAR. Mâ[ter]- / } \\
\text { ni (filius). ân(norum) LXX h(ic) s(epultus) e(st)? / c(um). } \\
\text { ux(ore). f(ilii). f(aciendum) [cur(averunt)] }{ }^{13} \text {. }
\end{gathered}
$$

El toro ocupa como siempre la parte inferior. La testuz del animal va decorada con un arpa. T. Ortego supone que al no quedar encajada esta figura, habría otra, hoy perdida, afrontada (fig. 6).

F) En una segunda estela de la misma procedencia, el toro mar-

10 T. ORtego, op. cit., 334, fig. 2.

$"$ T. Ortego, op.cit., 335, fig. 5.

12 T. ORTEGo, op. cit., 335, fig. 6.

13 T. ORtego, op. cit., 337 ss., fig. 7. 

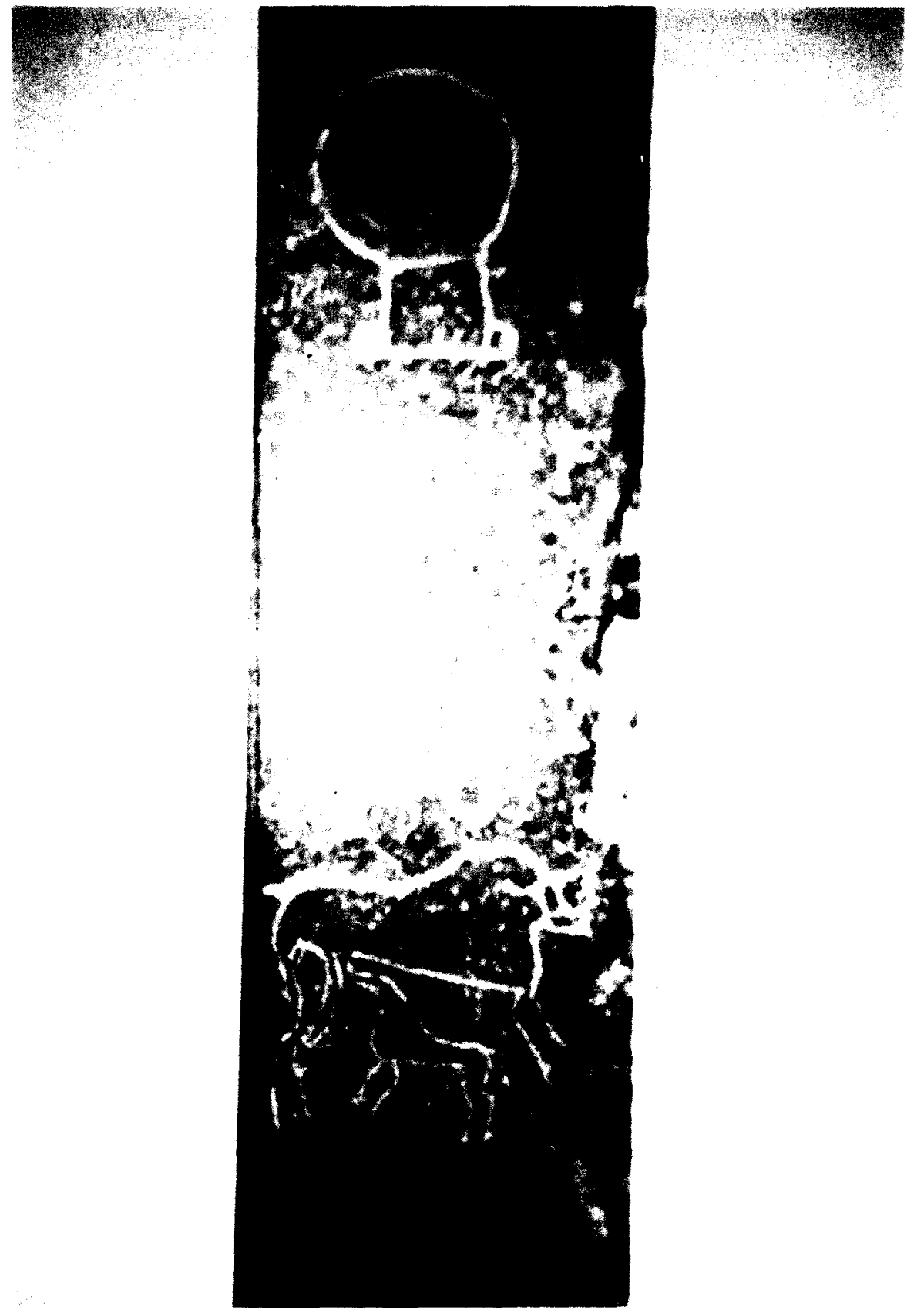

Fig. 1. Estela de Valloria. Soria. 


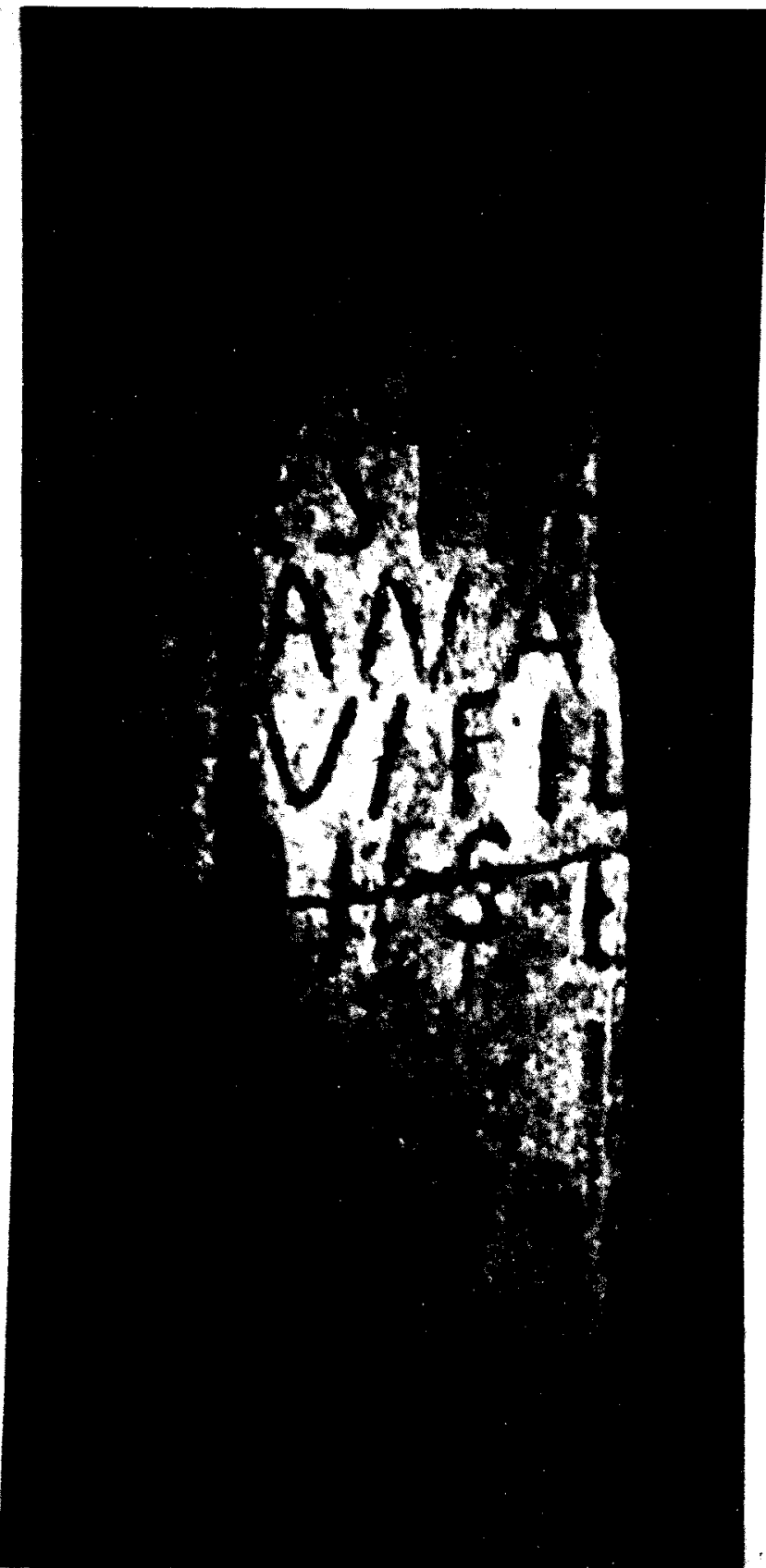

Fig. 2. Estela de Vizmanos. Soria. 


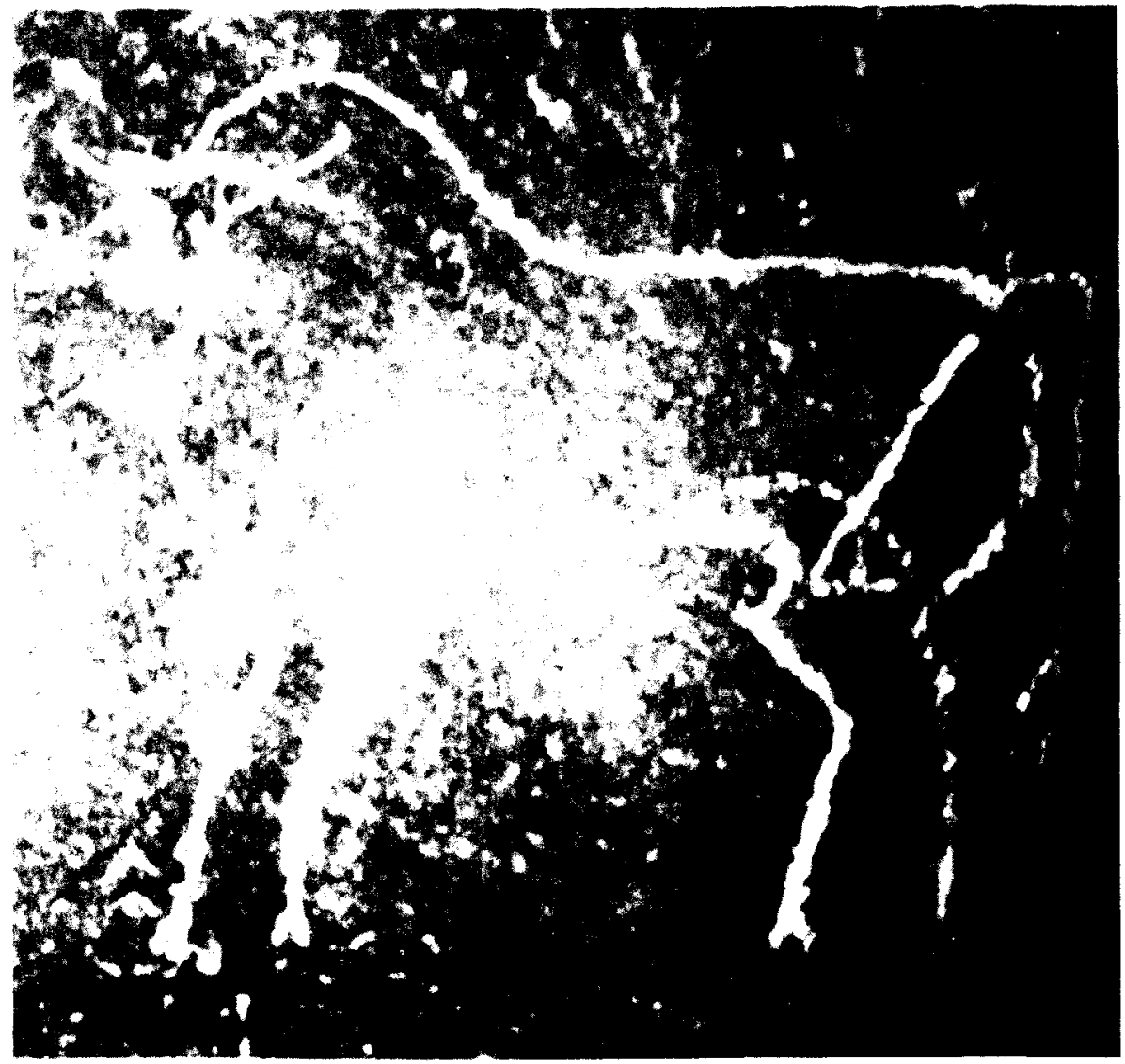

Fig. 3. Fragmento de estela de Vizmanos. Parte inferior. Se ha perdido la inscripción. Soria. 


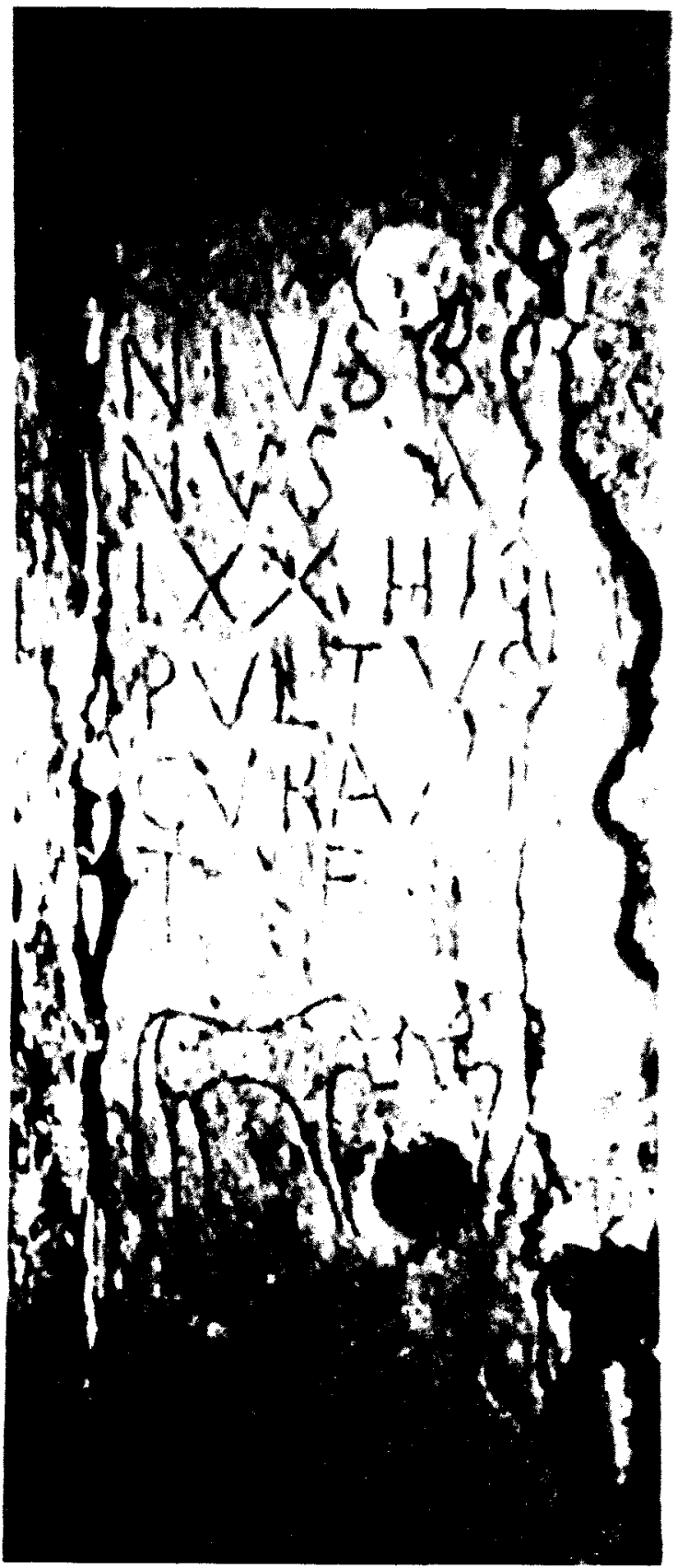

Fig. 4. Estela de Vellosillo. Soria. 


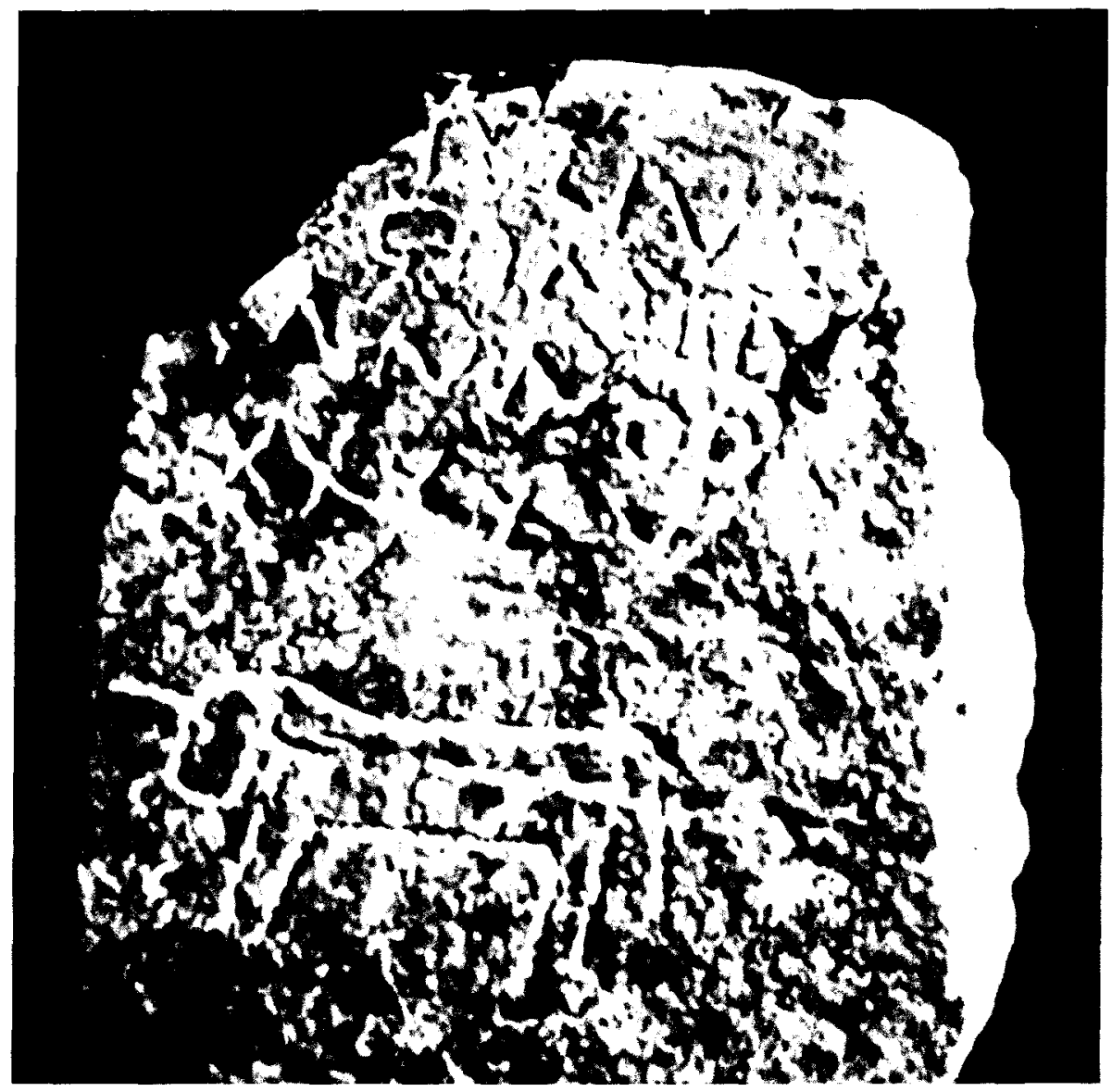

Fig. 5. Estela de Yanguas. Soria. 


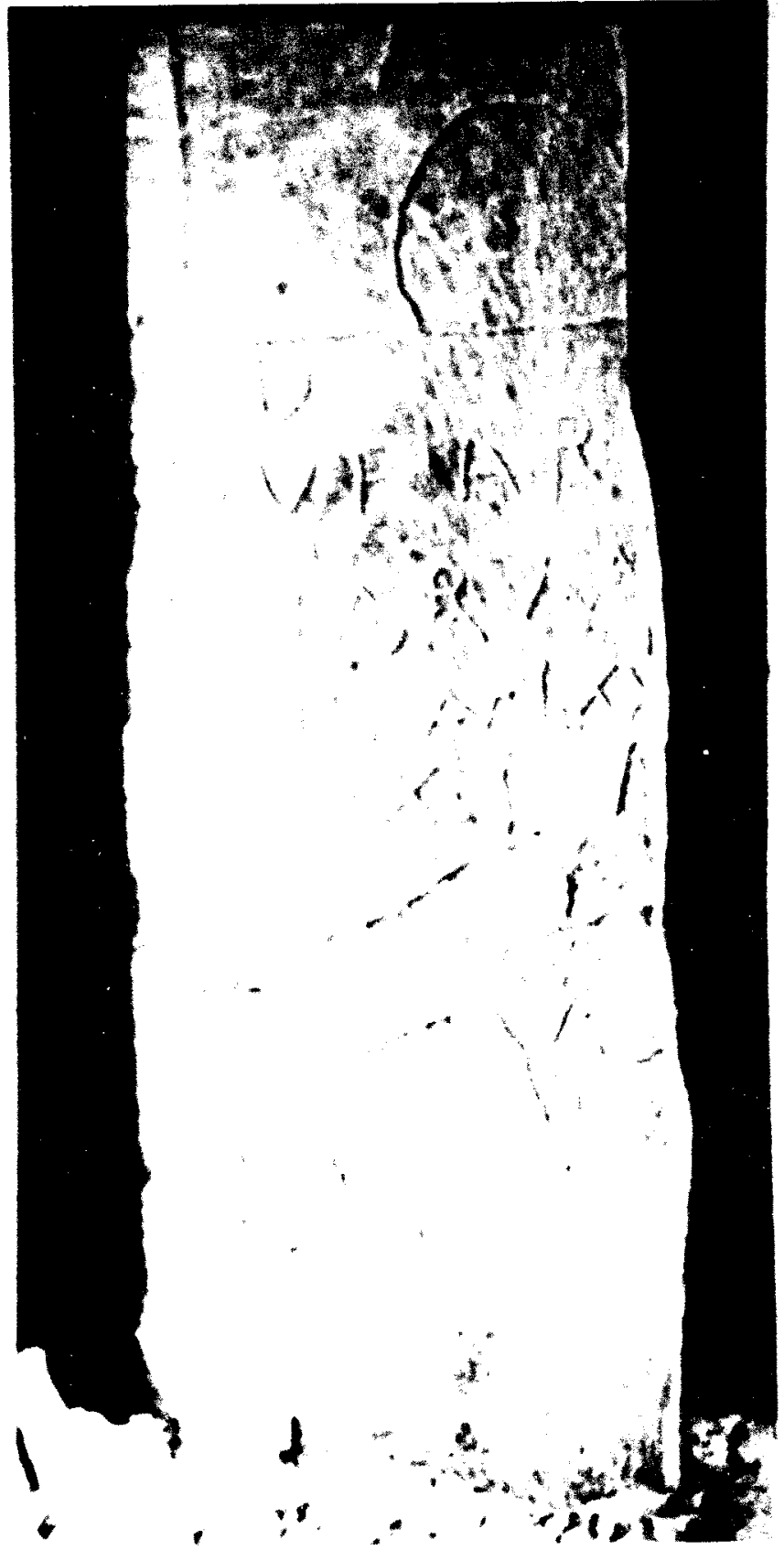

Fig. 6. Estela de El Collado. Soria. 
chando hacia la izquierda se encuentra en la parte inferior. La inscripción dice:

$$
\begin{gathered}
\mathrm{D} \text { (is) M(anibus) / Urs( ) } \mathrm{u}[1-] / \text { Fusci }[\mathrm{fil}(\mathrm{i}-)] / \text { Lupian[(a)e } \\
\text { fi] - / li(a)e su(a)e [an(norum)] / XV[—? }]
\end{gathered}
$$

Debajo del toro se colocó, siglos después, un símbolo cristiano, cruz sobre peana y en el borde derecho una inscripción con el año $1649^{14}$ (fig. 7).

A estas estelas con representaciones de bóvidos hay que sumar la hallada en Lara de los Infantes, también con vaca amamantando al ternero ${ }^{15}$.

En otros trabajos ${ }^{16}$ hemos estudiado el culto al toro. Aquí sólo queremos señalar que estas representaciones de bóvidos tienen un carácter funerario y confirman la tesis de $G$. López Monteagudo ${ }^{17}$ y de $\mathrm{A}$. Blanco ${ }^{18}$ del significado funerario de los verracos.

3. P. Piernavieja ${ }^{19}$ ha publicado los dos dioses indigenas que ha dado la Bética. La inscripción se halló en el Cerro de la Cava, Alcolea del Río (Sevilla). Dice así: Manus Aureli / palma pacatia i filius / posiissor leopardoru / denudator gimanasius Arescu. Manus es nombre propio relacionado con Mandonio, con significación de malo. El dedicante de la inscripción importaría leopardos con destino a las venationes de los anfiteatros. No poseía una flotilla personal, sino que la debía alquilar, lo que se indicaría con la figura de la barca, en la que está escrita la inscripción. Denudator fue interpretado como el oficio, pero Piernavieja rechazó esta tesis, pues es dificil admitir que un dueño de leopardos tuviera el oficio de un gimnasio. Denudator

${ }^{14}$ T. Ortego, op. cit., 340, fig. 8.

15 J. M. Blazquez, Historia de España. España Romana, fig. 154.

$16 \mathrm{~J}$. M. Blazouez, Diccionario de las religiones prerromanas de Hispania, 62 ss. Id. Religiones primitivas de Hispania I. Fuentes literarias y epigráficas, passim. Id. "Einheimische Religionen Hispaniens unter römischen Kaiserzeit", 190 ss. con toda la bibliografia menuda. Id. Primitivas religiones ibéricas II. Religiones prerromanas, passim. Id. Historia de España. España Romana, 276 ss.

${ }^{17}$ Expansión de los "verracos" y características de su cultura, Madrid, 1983. Id. "Las esculturas zoomorfas "célticas" de la Península lbérica y sus paralelos polacos", AESPA 55, 1982, 3 ss.

${ }_{18}$ "Museo de los verracos celtibéricos", BRAH 181, 1984, 1 ss.

19 "Denudator gimanasi v. S. Arescu", Homenaje a García y Bellido V, 359 ss. 


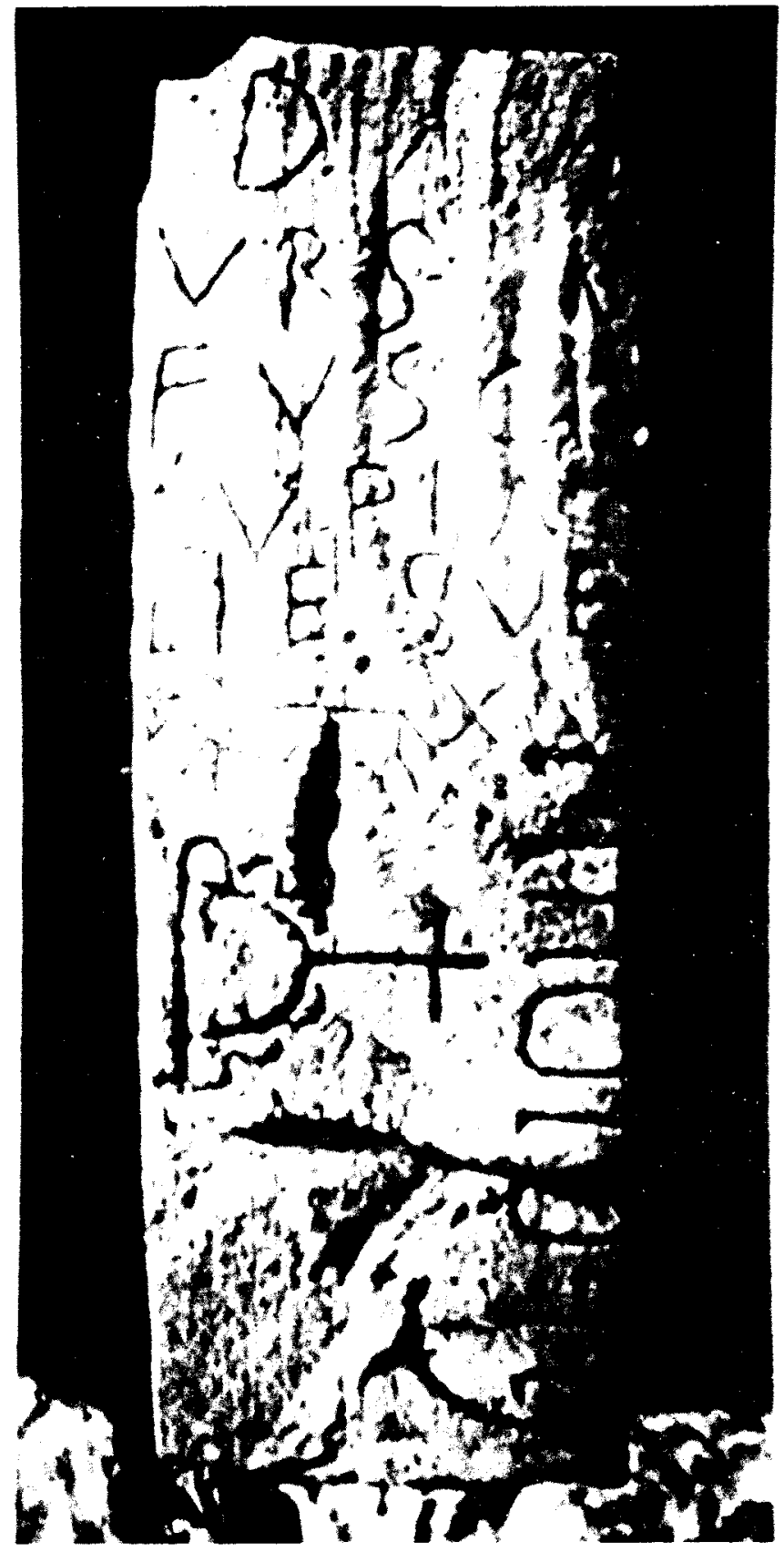

Fig. 7. Estela de El Collado. Soria. 
gimanasi equivalía a "gimnastes" o "gymnasta». Este autor piensa que en la última línea del epígrafe hay que leer v(otum) s(oluit) Arescu, que sería una deidad desconocida. Recoge P. Piernavieja varios términos con el tema en u: Luguei, de Peñalba de Villastar. Los progresos esperados son: uei>ui, con reducción en $-u$, con los nombres en $\longrightarrow$, según este cuadro:

1. Luguei

2. Vanditatideaic $\mathrm{VI}$

Bandeibriyaleac VI

Revelanganidaeig $\mathrm{VI} \rightarrow$ Renelanganitaec $\mathrm{O}$ Lucubo

$\downarrow$

3. Berraloceg $\mathrm{V}$

Locoubu V

Eciais V

Evvedutoni V

Laroc $\mathrm{V}$

El dativo de la barca bética pertenece al último grupo. No es un nombre abreviado (fig. 8). Arescu es probablemente el nombre de un dios y no de diosa, protector probablemente de los viajes por agua. Es con Borea Cantibedoniensis, la única divinidad indígena que ha dado la Bética (fig. 9).

$P$. Piernavieja ha recogido las inscripciones que contienen el nombre Mannus o derivados. Tan sólo se recogen aquí las que tienen un teónimo hispánico. Esta son:

A) Coria (Cáceres) Arientia[e] Arentio / Amru/naeco / Silo / Mani(filius)/v(otum) s(olvit) l(ibens) m(erito).

B) Lugo: Aug. Lar.sa/crum. Laribus/Vialïb.M.M. / Annius.Varus/ [u]eteranus/(ducenarius) Leg. G. Pa/ter et filius/ex voto.

C) Idanha -a-Velha: Bendei/brialeac/cui.Severu/s. Abrimi. f(ilius)/v(otum).s(olvit). Brialeacui puede ser el apelativo.

D) Gueiriz: Dua/tius / Apinis / Bandi/tatideaic/ui/vocto/tolit i(ussu)?

E) Santa Cruz de Layo (Lugo): Cueve/berral/ocegu/[e]x voto / Flavius Valeria/nus.

F) Cáceres: Ec...su / Mailo/nus Le/uri a.p./l.a. Piernavieja reconstruye Ecia isu o Egiaisu. Está borrado el topónimo a propósito. 

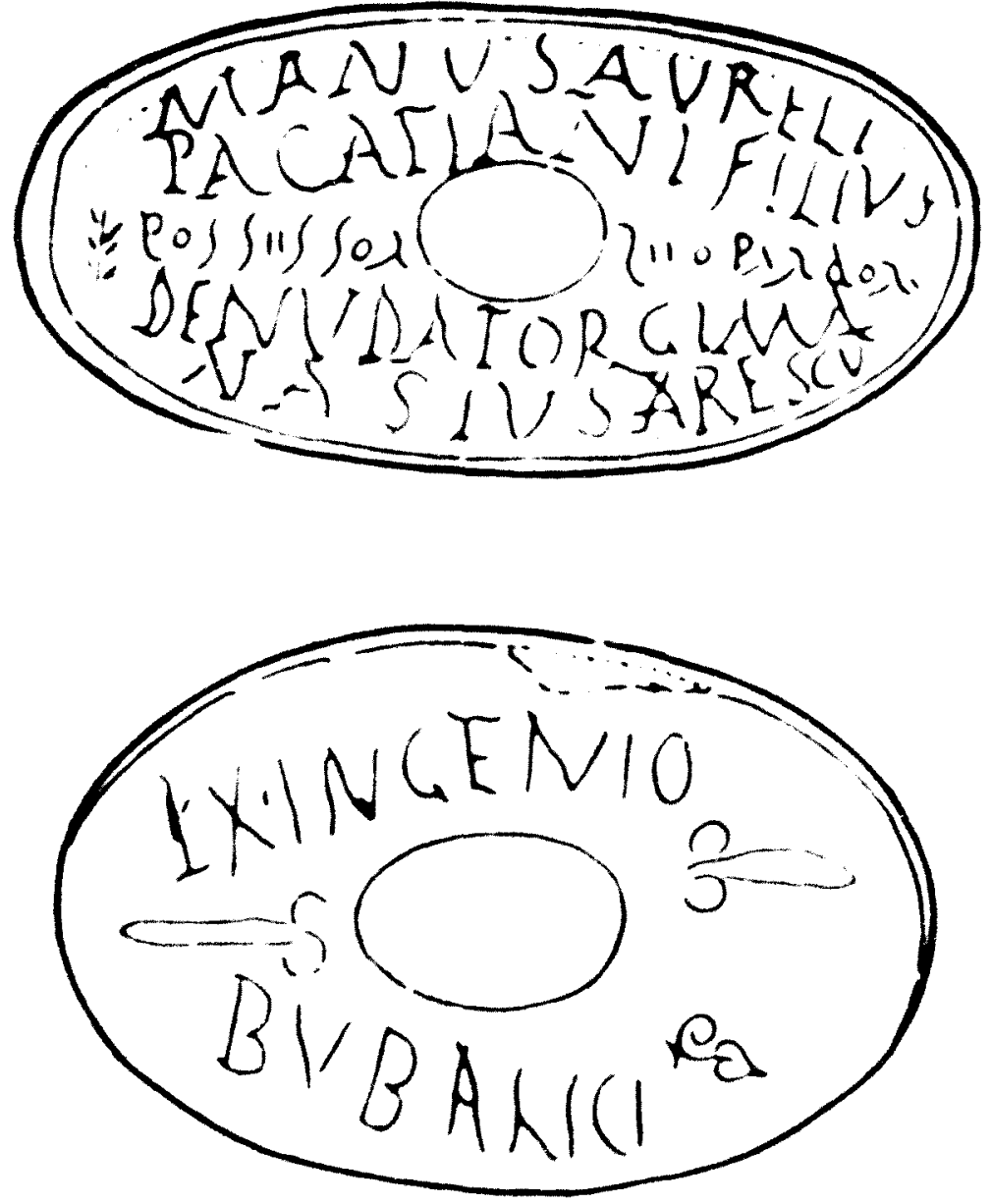

Fig. 8. Barca de Alcolea del Río. Sevilla. 


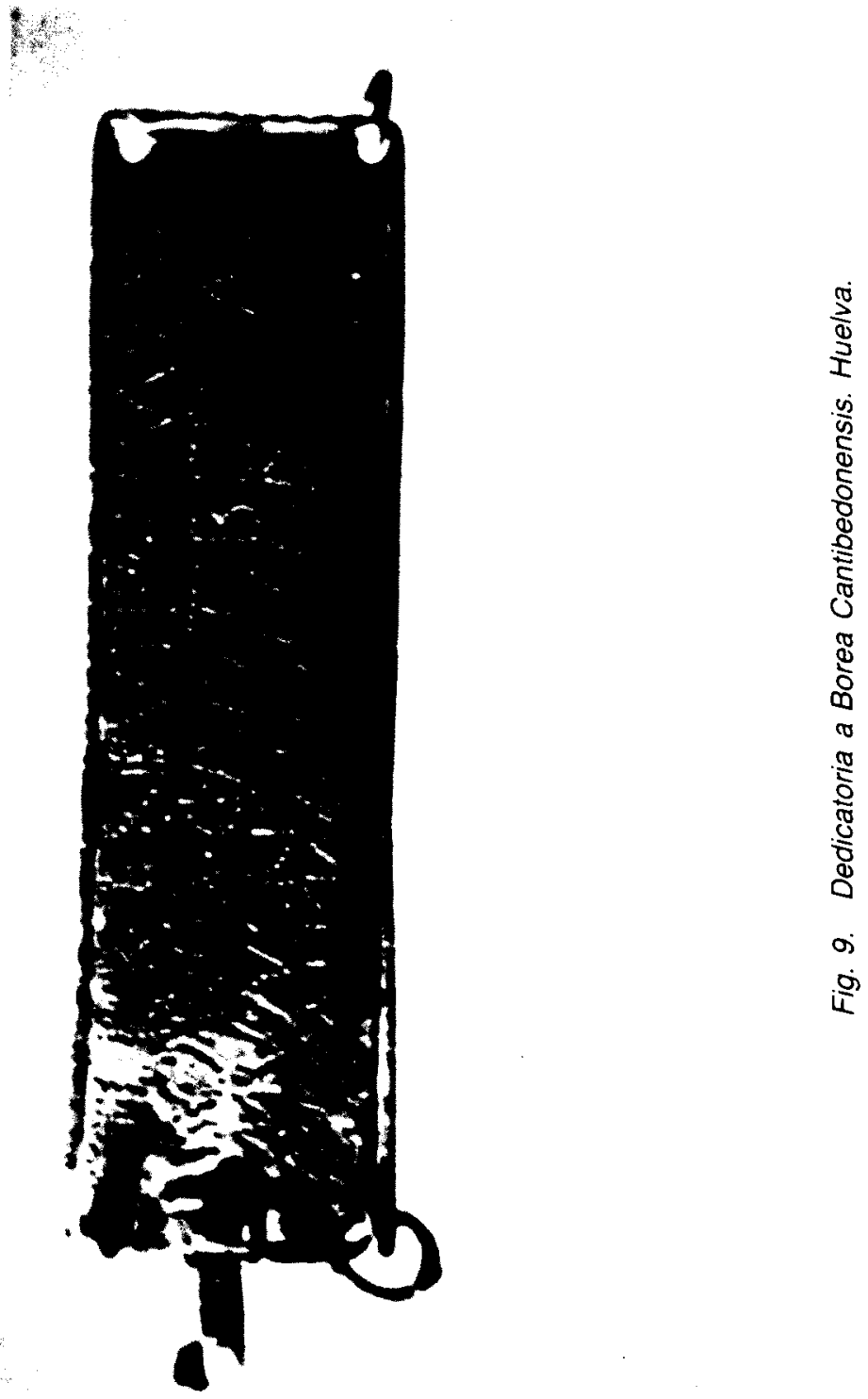


Tal vez el teónimo se relacione con el Egueisui de Peñalba de Villastar y con otros como Eguaesus, con reducción $-g u->a$.

G) Naraval (Tineo, Asturias): C. Ser Secun / Evedutoniu / Barciaeco/v.s.I.m. Piernavieja piensa que Barciaecus es un topónimo y Evedutonius (poco probable es Eve-duonius) el teónimo.

H) Corral de Vascos (Portugal): Larocu Ama Pitil/i filia lib./animo vo/tum retulit/pro merito. El dios es un topónimo.

I) Sinoga (Otero de Rey, Lugo): Lucoubu Arquien(o) / Silonius / Silo/ex voto.

J) Linaron (Sober, Lugo): Lucubo / Arquieno b[ono] / C. Iulius hispanus/v.s.I.m.

K) Peñalba de Villastar (Teruel): Eniorosei/uta. Tigino tiatunei/trecaias to. Lugei/araianom. Comeimu/eniorosei. equeisuique/ ogris, olacas. Togias. Sistat. Lugeiei. tiaso / Togias.

L) Indanha: Rectus/Rufi f/Reve/langa/nidaeigni v.s.

M) Proença: [Re]evelanganitaeco/[es]t hostia deliganda/Lucanus Adiei $f$.

N) Entre Niebla y Moguer: Celer Erbuti. P. Limicus / Borea. Cantibedoniesi/muneris.tesera. dedit. anno. M. Licinio. cos Borea es un teónimo. Canti tiene la misma raiz que Cantria y Cantaber, Celer es probablemente un gladiador que ofrecía la tessera a Borea.

N) Sierra de Monsanto: L.C.O. / Mar/ti.Boro/a.l.v.s. P. Piernavieja, apoyado en la inscripción de Mars Borus propone que Borea sea también un dios asimilado a Marte.

P) Ponferrada: T. Pomp/eiüs Pa/ternus Mandica/ae v.m.s.

Q) Madre de Deus, Sintra (Portugal): Cassia Mate/er(na) Man/diceo/v.s.l. Este dios y el anterior parecen estar relacionados con los caballos ${ }^{20}$. P. Piernavieja se pregunta si no sería una pareja de dioses hermanos.

20 Relieves del despotes hippon han aparecido en número de 11, pero entre los iberos: J. J. EIROA «Noticia de dos representaciones de Potnios Hippon encontradas en Lorca (Murcia)", Anales de Prehistoria y Arqueología 3, 1987, 123 ss., con el catálogo de todas las piezas. M. P. SAN Nicolas, "Un nuevo relieve del "domador de caballos" procedente de la Encarnación (Caravaca, Murcia)", Pyrene 19-20, 277 ss. Otra imagen está probablemente en un bocado de caballo de Cancho Roano (Badajoz) (J. MALuQuer, M. E. AuBET, Andalucia y Extremadura, Barcelona, 1981, 324 ss. Fig. 37.). 
4. G. López Monteagudo ${ }^{21}$ ha estudiado la significación de las cabezas cortadas en Hispania, concluyendo que la presencia del torques en algunas de estas cabezas y en las esculturas de guerreros lusitanos les confiere un carácter divino o casi divino en relación con un culto al héroe muerto y con una simbología de caráctar ctónico y funerario, ligada a una divinidad que podría identificarse con Marte.

5. Precisamente A. Blanco ${ }^{22}$ ha llamado la atención sobre una mención de Marte que había pasado desapercibida de los estudiosos. T. Livio, al referir los combates que sostuvieron los indigenas en Cartagena con ocasión de las honras fúnebres organizadas por Escipión el Africano en honor de su tío y padre (Liv. 28.21), escribe de los combatientes "que no aceptarían a ningún juez de los hombres ni de los dioses si no era a Marte». A Blanco pone en relación esta mención de Marte con el conocido texto de Macrobio referente al Marte de Acci, llamado Netón.

6. El mismo A. Blanco ${ }^{23}$ relaciona grupos de combatientes, como los guerreros de Porcuna, las luchas al son de la música de la cerámica de Liria, las luchas de los relieves de Osuna, los guerreros combatiendo de Elche, con los funerales de Viriato descritos por Apiano (Iber. 71) y con los de Cartagena descritos por T. Livio (28.21). El varón con un macho cabrío a sus espaldas de Obulco podría ser una imagen de Marte, según este autor ${ }^{24}$.

7. M. Almagro ${ }^{25}$ publica una serie de inscripciones dedicadas a las Lares, a Ataecina, etc.

\section{Estos son:}
A) L(aribus) Via(libus)/ Manca / pro Elv[i]a Marce[II]a/v(otum) $\mathrm{s}$ (olvit) ${ }^{26}$.
B) $[\mathrm{D}] \mathrm{o}[$ minae $] \quad \mathrm{s}$ (anctae)/tur(obrigensi) $\mathrm{A}($ taecinae)/ Ulenses ar(am) prosuerunt ${ }^{27}$.

21 "Las "Cabezas cortadas" en la Península Ibérica", Gerión 5, 1987, 245 ss.

22 "La esculturas de Porcuna II. Hierofantes y cazadores", BRAH 1985, 1988, 15 ss.

${ }^{23}$ Op. cit. 15 ss.

${ }^{24}$ A. BLANCO, op. cit. 14.

${ }_{25}$ Segobriga II. Inscripciones ibéricas, latinas paganas y latinas cristianas, Madrid, 1984 , pág. 71 y ss.

${ }^{26}$ M. Almagro, op. cit., pág. 71 y ss. n. ${ }^{\circ} 9$.

${ }^{27}$ M. Almagro. op. cit., pág. 80 y ss. n. ${ }^{\circ} 14$. 
C) Deo Aironi fecit familia/ocule(n)s(is) use(tana?)/ C(aius) Titiniu[s] Prispinu[s] ${ }^{28}$.

D) $\ldots$ Pendusae... [Vict] orinus/ $[v($ otum) $] \quad s$ (olvit) a(nimo)/(1/ ibens) ${ }^{29}$.

E) Leioss(a)e/ C(ornelia) Bessuca/pro filio/v(otrum) I(ibens) $\mathrm{r}$ (eddidit) $\mathrm{m}$ (erito) ${ }^{30}$.

F) [A]lbanus [A]elmanio v(ivus)/s(olvit) v(otum) I(ibens)/m(erito) ${ }^{31}$. (fig. 10).

G) Amma/sacr(um)/ex. voto ${ }^{32}$.

H) Valerius Tir/o Dialco votu/m libes me/rito la [etus solvit] ${ }^{33}$ (fig. 11).

8. P. de $\mathrm{Palol}^{34}$ ha publicado recientemente una serie de inscripciones consagradas a las Matres y a otros dioses indígenas. Son las siguientes:
A) Matrib[ ] / Brigeacis / L(ucius) Aelius / Phainus/v(otum) s(olvit) l(ibens) m(erito) ${ }^{35}$.
B) Matribus / Endeiteris / T(itus) Arrius / Natalis ${ }^{36}$ (fig. 12).
C) Matribus / Endeiteris / Felix / Priscae/v(otum) s(olvit). I(ibens). $\mathrm{m}$ (erito) ${ }^{37}$ (fig. 13).
D) Matribus/ Abascant/tus. Mar/celae./ex.voto ${ }^{38}$ (fig. 14).
E) Arria Not/his Matribus/pro secundo/v(otum) s(olvit) l(ibens) m(erito) ${ }^{39}$ (fig. 15).
F) Matrib(us). T(itus) Racili(us). Valeri/anus. ex voto(o) ${ }^{40}$ (fig. 16).

\footnotetext{
${ }^{28}$ M. Almagro, op. cit., pág. 83 y ss. n. ${ }^{\circ} 15$.

${ }^{29}$ M. Almagro, op. cit., pág. 85 y ss. n. ${ }^{\circ} 16$.

${ }^{30}$ M. Almagro, op. cit, pág. 86 y ss. n. ${ }^{\circ} 17$.

${ }^{31}$ M. Almagro, $o p$. cit., pág. 87 y ss. n. 18.

${ }^{32}$ M. Almagro, op. cit., pág. 89 y ss. n. ${ }^{\circ} 19$.

${ }^{33}$ M. Almagro, op. cit, pág. 90 y ss. $n .{ }^{\circ} 20$.

${ }^{34}$ Clunia II. La epigrafía de Clunia, Madrid 1987.

${ }^{35}$ P. DE PALOL, op. cit., pág. 27 n. ${ }^{\circ} 12$.

${ }^{36}$ P. DE PALOL, op. cit., pág. 28 n. ${ }^{\circ} 13$.

${ }^{37}$ P. DE PALOL. op. cit., pág. 28 n. ${ }^{\circ} 14$.

38 P. DE PALOL, op. cit., pág. 29 n. 15.

${ }^{39}$ P. DE PaLol, op. cit., pág. 30 n. ${ }^{\circ} 16$.

${ }^{40}$ P. de Palol, op. cit., pág. 30 n. $^{\circ} 17$.
} 


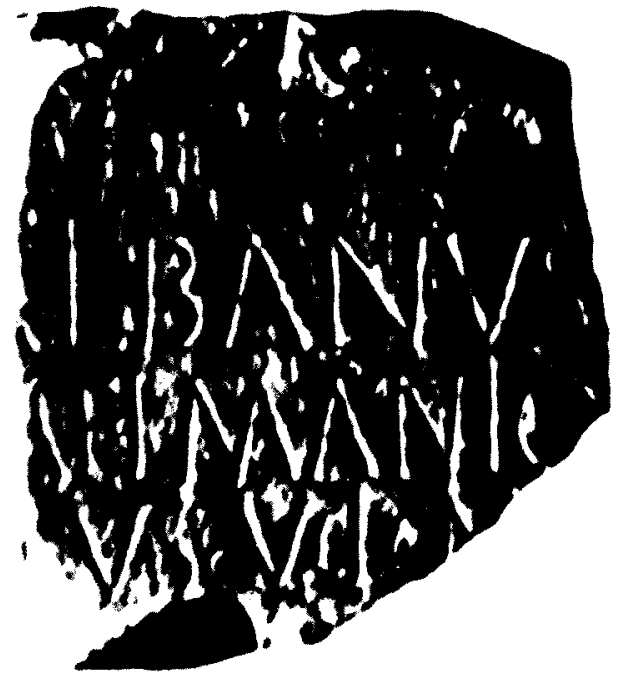

Fig. 10. Inscripción de Aelmancio. Segóbriga. 


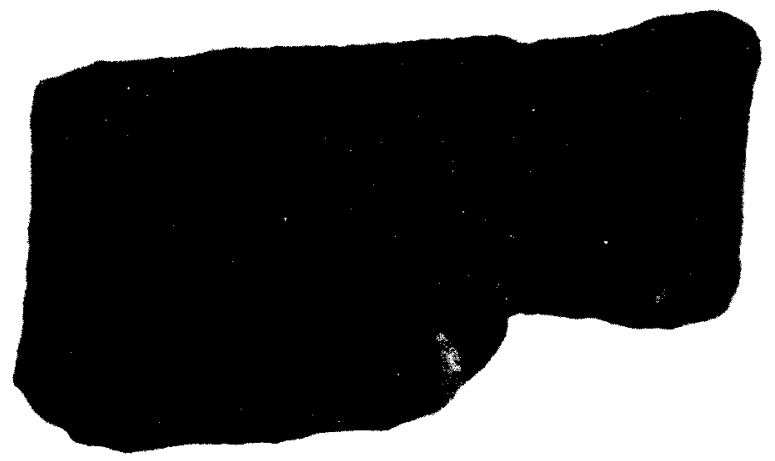

Fig. 11. Inscripción de Dialco. Segóbriga. 


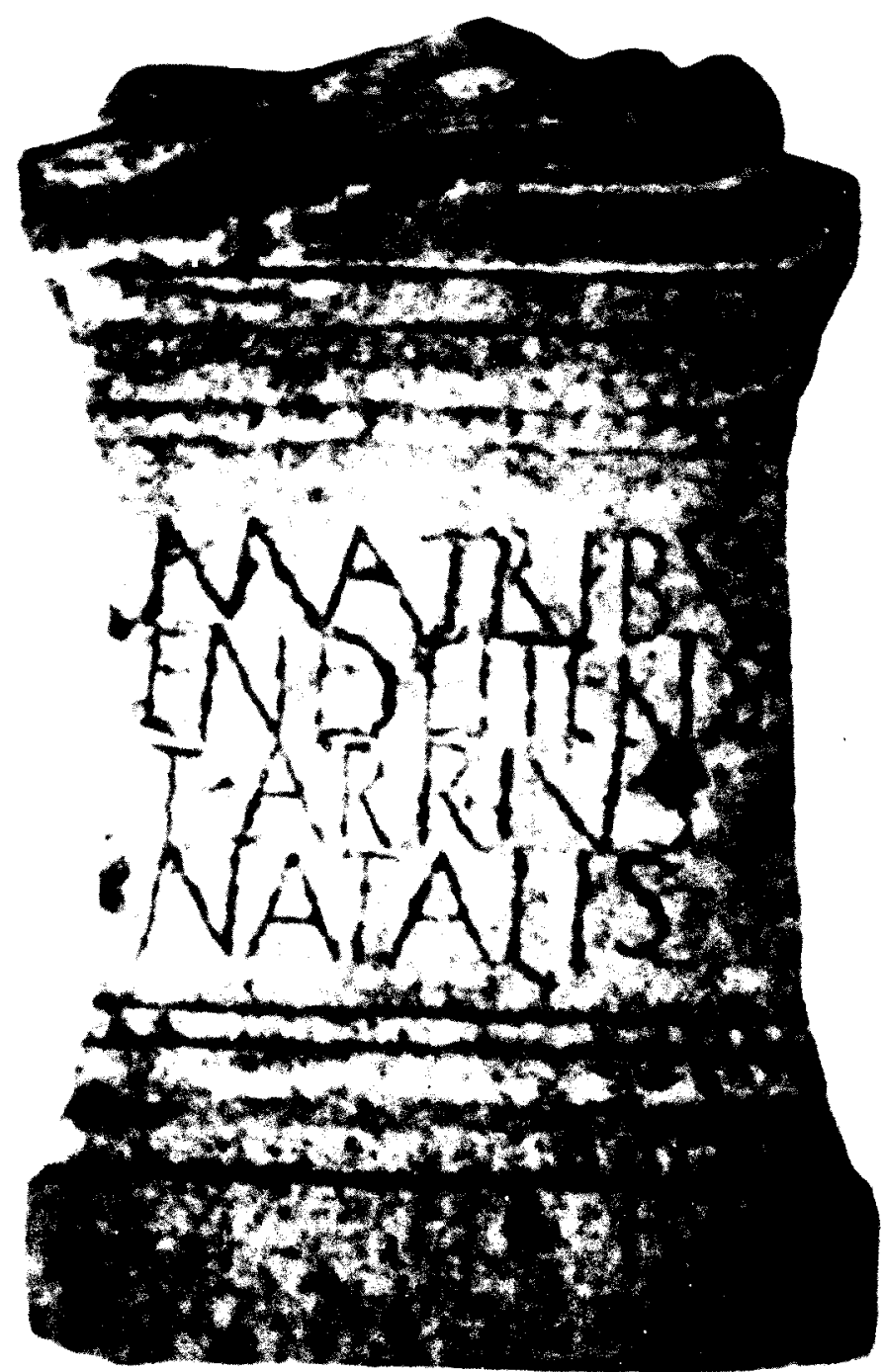

Fig. 12. Ara de las Matres. Endeiterae. Segóbriga. 


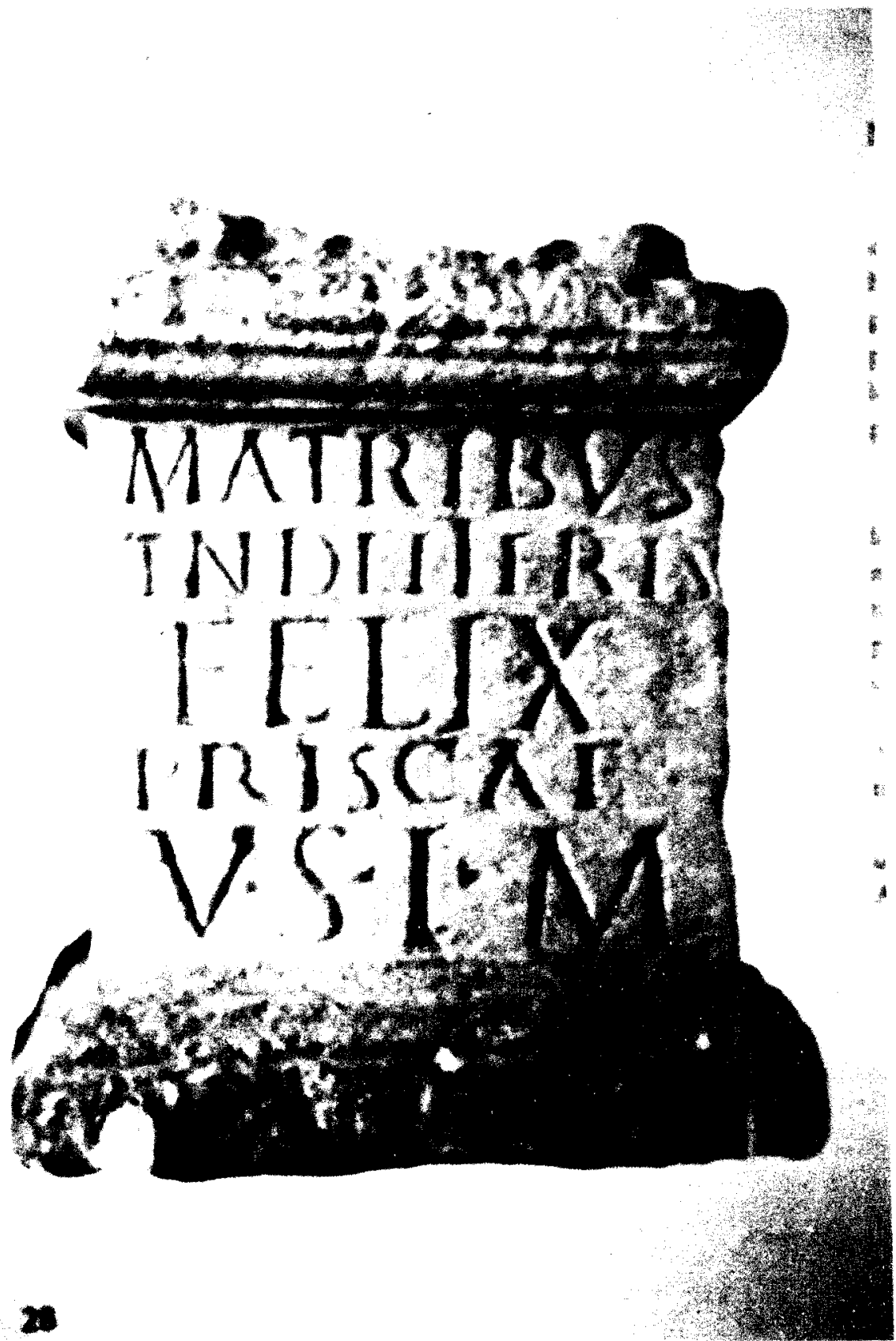

Fig. 13. Ara de las Matres. Endeiterae. Segobriga. 


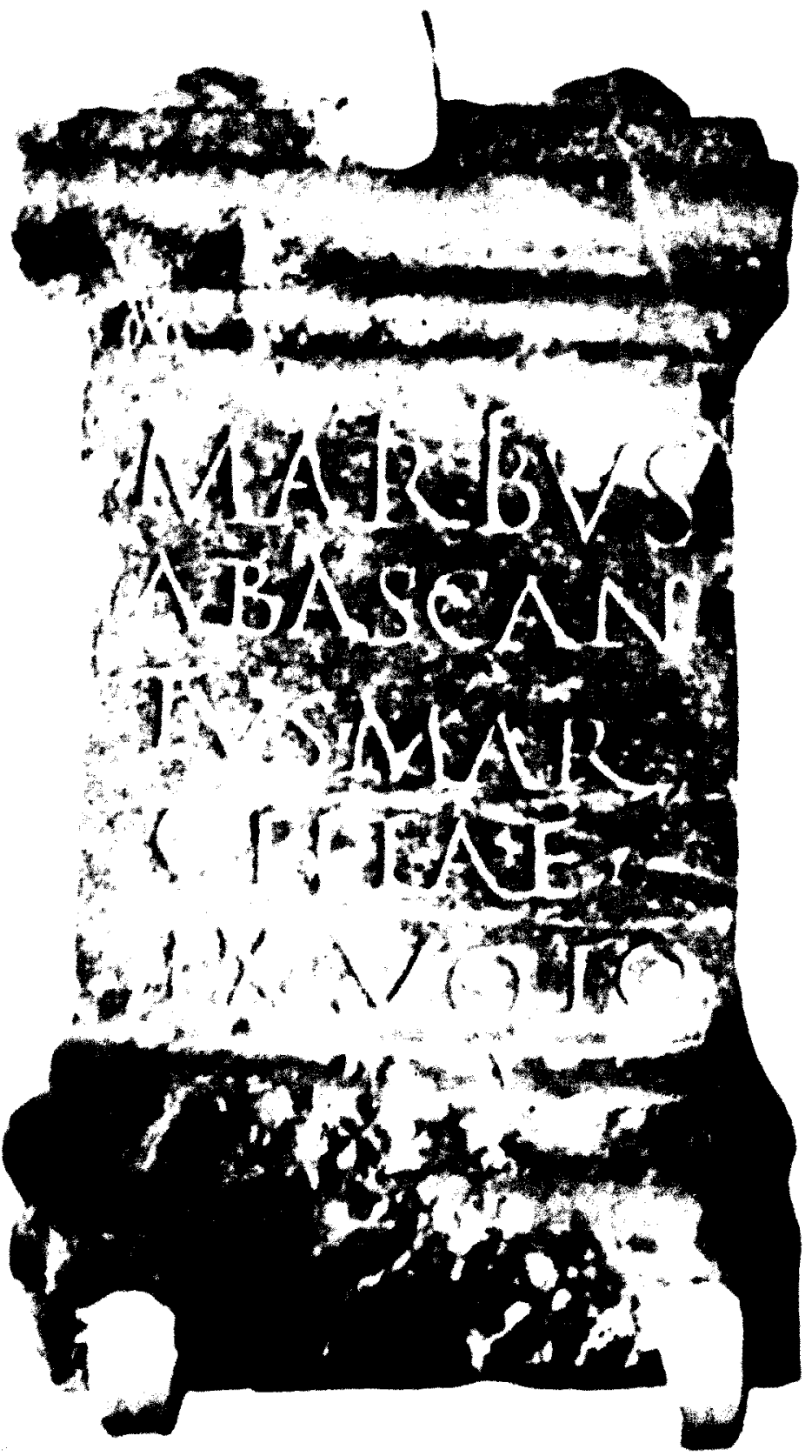

Fig. 14. Ara de las Matres. Segóbriga. 


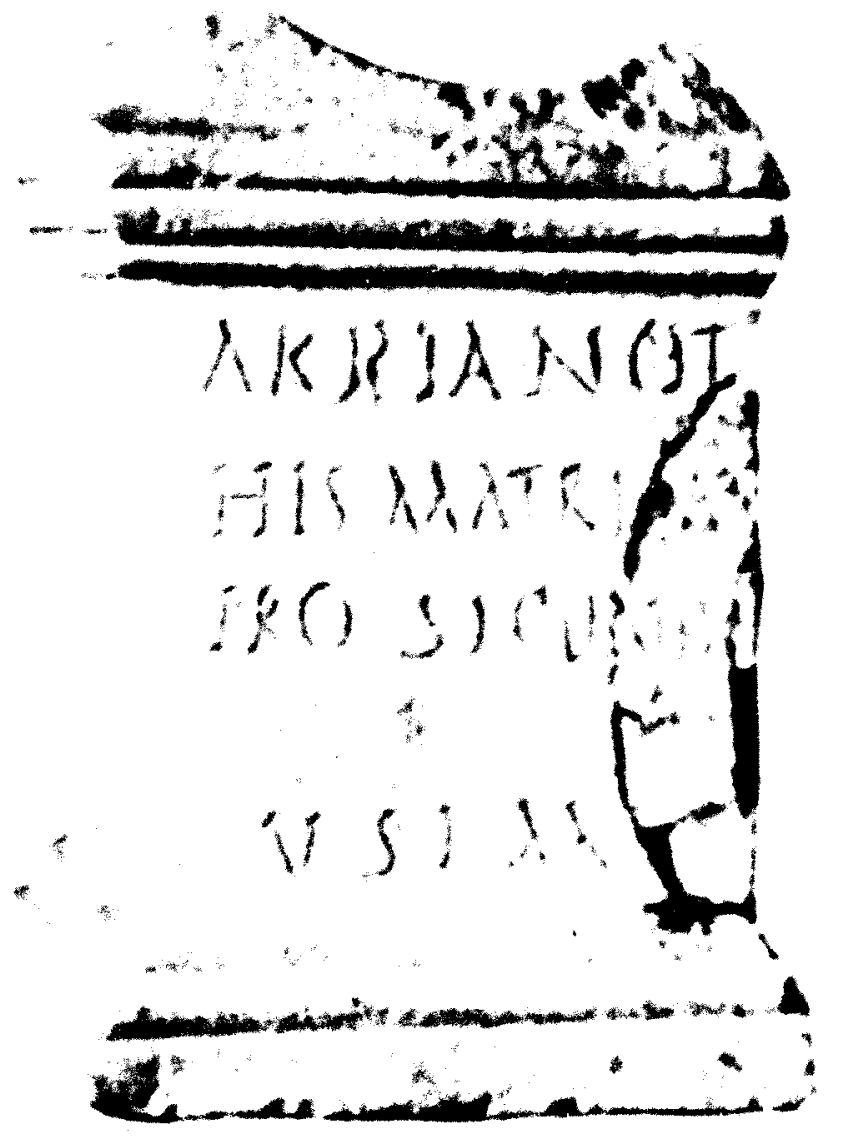

Fig. 15. Ara de las Matres. Segóbriga. 


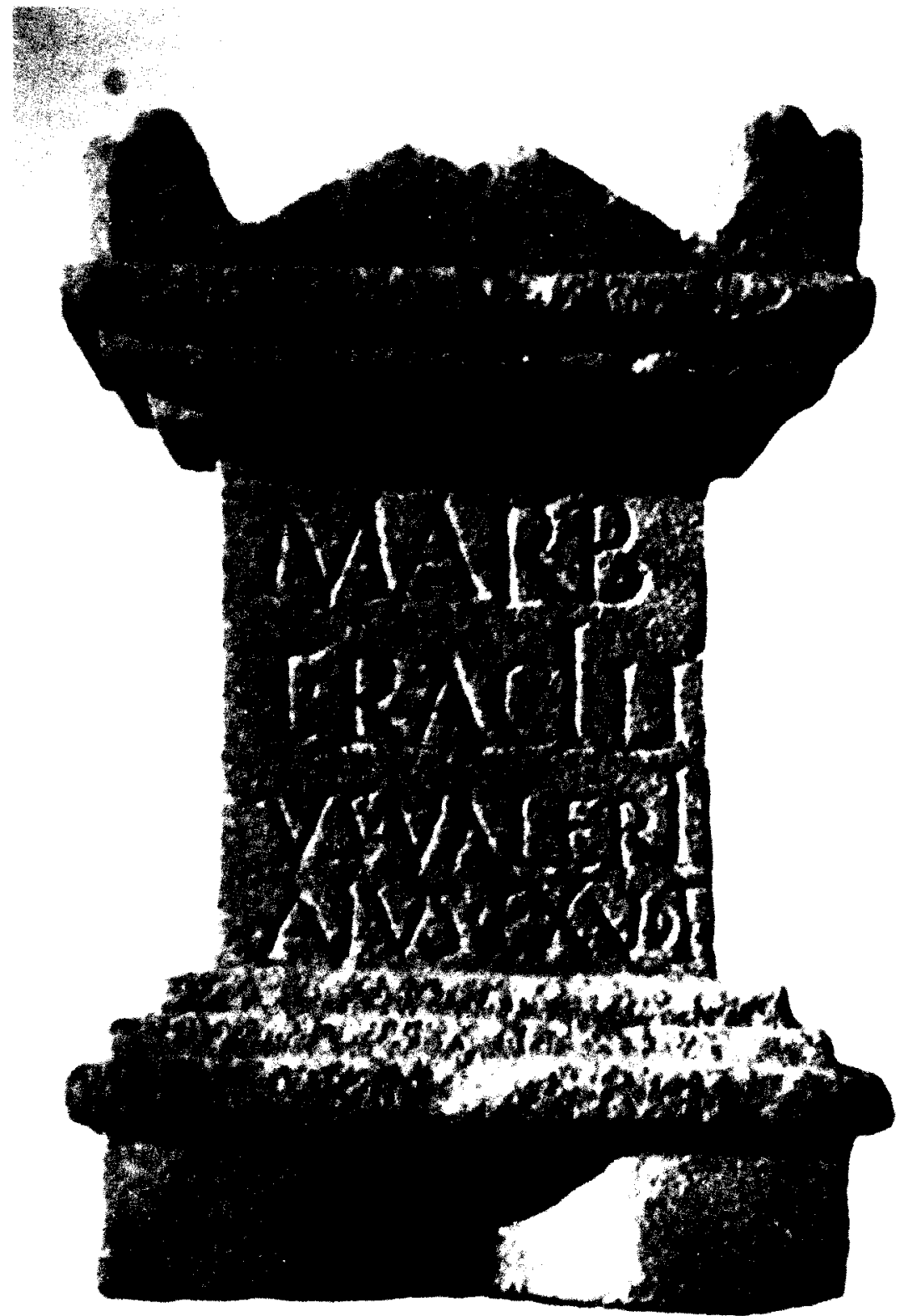

Fig. 16. Ara de las Matres. Segóbriga. 
G) Neptuno deo/ $[\ldots] \circ / \ldots . /[\ldots] \mathrm{E} / . .{ }^{41}$.

H) V. Rebu/rnus.ex vi/su.Larib/us. vial/ibus. sa/crum/r.I.m. ${ }^{42}$.

9. J. Caro Baroja ha publicado la reedición del libro ya clásico Los Pueblos de España, San Sebastián 1977, donde dedica varias páginas a la religión de los pueblos de la España primitiva. Se publican unas magníficas fotos relacionadas con la religión que son:

A) Estela vadiniense de Maisontina, con caballo debajo de la inscripción y cruz sobre él. Demostraría el carácter funerario del caballo entre los vadinienses. La cruz es un símbolo astral y no es prueba de cristianización ${ }^{43}$.

B) Estela de Anchearriaga, Oyarzun, Guipúzcoa, con jinete en la parte superior. Probaría el carácter funerario del tema del jinete en estelas ${ }^{44}$.

C) Estela de Carcastillo, Navarra, con símbolos astrales, rosetas, lunas y arcos, todo con carácter funerario ${ }^{45}$.

D) Estela de Corao, con cruz arriba, que es un símbolo funerario, pero no cristiano, posiblemente astral ${ }^{46}$.

E) Estela de Terentius Bodero, vadiniense, con svastica, en la parte superior, con sentido funerario.

F) Estela del Museo de Pontevedra con representación del difunto de cuerpo entero ${ }^{47}$.

G) Estela de Clunia con roseta, que indicaría una concepción astral de la ultratumba ${ }^{48}$.

H) Estela de Sestio de Munigalico, Valduno, con dos jarros, alusivos a libaciones funerarias ${ }^{49}$.

I) Estela de Talavo, Cornellana, con retrato del difunto ${ }^{50}$.

${ }^{4} P$. DE PALOL, op. cit., pág. 31 n. ${ }^{\circ} 19$.

42 P. DE PALOL, op. cit., pág. 27 n. 11.

43 J. Caro Baroja, op. cit., pág. 89.

${ }^{44} \mathrm{~J}$. Caro Baroja, op. cit., pág. 91.

45 J. Caro Baroja, op. cit., pág. 93.

46 J. Caro Baroja, op. cit., pág. 101.

47 J. Caro Baroja, op. cit. pág. 104.

4 J. Caro Baroja, op. cit., pág. 104.

49 J. Caro Baroja, op. cit., pág. 105.

so J. Caro Baroja, op. cit., pág. 111. 
J) Ara dedicada al dios Vacocaburius, de Astorga ${ }^{51}$.

K) Estela de Mars Cariociecus de Tuy, que es el dios asimilado a Mars, al que alude Estrabón ${ }^{52}$.

L) Estela de Bearin, Navarra, con el difunto acompañado de símbolos astrales y cipreses, símbolos funerarios ${ }^{53}$.

LL) Ara de Vestio Alonieco de Lourizán con svástica ${ }^{54}$.

M) Estela de un labrador con toro y palas. El toro no tendría carácter funerario, sino que aludiría a la profesión del difunto, al igual que las palas ${ }^{55}$.

N) Estela de Ocariz, Alava, con ramos de vid, símbolo de inmortalidad, probablemente relacionados con Dionisio, tema frecuente en las estelas navarras ${ }^{56}$, y con ciervo perseguido por perro ${ }^{57}$. La caza es de carácter funerario, como en la estela de Villatuerta, Navarra ${ }^{58}$.

N) Estela de Gastiacín, Navarra, con bóvido, con carácter funerario, árboles de carácter también funerario y ramos de vid, posiblemente vinculados con Dionisio. Las vides son tema frecuente en lápidas de Moesia ${ }^{59}$.

Estudia J. Caro Baroja ${ }^{60}$ el carácter religioso de la danza de los celtíberos en las noches de plenilunio. Examina los textos de Estrabón (3.3.7.), en sus variados aspectos referentes a Mars, el culto a la luna, a los augurios (S.H.A. Vit. Alex. Sev. 27.6) entre los vascones, los galaicos (Sil. Ital. 3.344) y los cántabros tamáricos (Plin. 31.23-24).

El texto estraboniano de que los galaicos son ateos lo interpreta en el sentido de que los nombres no se podian pronunciar.

51 J. Caro Baroja, op. cit., pág. 105.

52 J. Caro Baroja, op. cit., pág. 119.

53 J. Caro Baroja, op. cit., pág. 120.

54 J. Caro Baroja, op. cit., pág. 123.

55 J. Caro Baroja, op. cit., pág. 124

56 C. CAStillo y otros, Inscripciones romanas del Museo de Navarra, Pamplona 1981, láms. XLIV, XLVII.

57 J. Caro Baroja, op. cit, pág. 125.

58 J. Caro Baroja, op. cit., pág. 117.

59 J. Caro Baroja. op. cit, pág. 130.

${ }^{60}$ Op. cit., pág. 86 
Las lápidas reflejan según J. Caro Baroja ${ }^{61}$ un gran politeismo y animismo.

Finalmente J. Caro Baroja ${ }^{62}$ analizó el culto lunar entre los vascos, que puede remontar a creencias antiguas.

El nombre de la luna es tabú. Era la luz de los muertos. Se vinculaba con la muerte. El calendario vasco era lunar. También hay vestigios del culto a la luna, al dios del cielo, al sol y a la tierra.

10. J. M. Blázquez y S. Jiménez ${ }^{63}$ han publicado un dios tricéfalo de la villa de Montemayor, Salamanca, que está en relación con los dioses tricéfalos galos.

11. U. Espinosa ${ }^{64}$ ha publicado algunos teónimos de La Rioja, de los que algunos son nuevos. Son los siguientes: Caldo Uledico, en el Rasillo de Cameros ${ }^{65}$; Durcetio ${ }^{66}$, en San Millán de la Cogolla; Lares Viales ${ }^{67}$, en Cervera del Rio Alhama; Matres useae ${ }^{68}$, en Canales de la Sierra; Mercurio Viseceo ${ }^{69}$, en Agoncillo; Obiana en Estollo ${ }^{70}$.

12. U. Espinosa y L. M. Usero ${ }^{71}$ han dado a conocer unas inscripciones de La Rioja, que pertenecen al mismo grupo que las publicadas por T. Ortego, cuyas lecturas han corregido y son seguidas por nosotros en este sentido. Las nuevas son las siguientes:

A) Estela de Vizmanos:

Cornel[i]us Viator Ara-/ncisis f(ilius) ân(norum) L Corneliu(s)/ Valens f(ilius) ân(norum) XXV et Âe(milius).Severus Agi.rseni/

${ }^{61}$ Op. cit., pág. 95 y ss.

${ }^{62}$ Op. cit., pág. 250.

${ }^{63}$ "Dios tricéfalo de la villa de Montemayor (Salamanca)", AEspA, 58, 1985, pág. 125 y ss.

64 Epigrafía romana de la Rioja, Logroño, 1986.

${ }^{65}$ U. ESPINOSA, op. cit., pág. 78 y ss., n. ${ }^{\circ} 60$.

${ }^{66}$ U. EsPinOSA, op. cit., pág. 59 y ss., n. ${ }^{\circ} 40$.

${ }^{67}$ U. Espinosa, op. cit., pág. 21 y ss., n. ${ }^{\circ} 3$.

${ }^{68}$ U. ESPINOSA, op. cit., pág. 81 y ss., n. ${ }^{\circ} 63$.

${ }^{69}$ U. ESPINOSA, op. cit., pág. 30 y ss., n..$^{\circ} 10$.

70 U. ESPINOSA, op. cit, pág. 38 y ss., n. ${ }^{\circ} 39$.

71 "Eine Hirtenkultur im Umbruch. Untersuchungen zu einer Gruppe von Inschritten aus dem conventus Caesaraugustanus (Hispania Citerior)", Chiron, 18, 1988, pág. 477 y ss. 
f(ilius) ân(norum) XXXV f(aciendum) c(uravit) matê[r]/ s(it).vobis.t(erra.l(evis).hic se[p]-/ulti sunt.

En la parte inferior hay dos toros afrontados, atados a un poste y debajo un jinete ${ }^{72}$ (fig. 17).

B) Yanguas. Dice asi la inscripción:

Minici-/a.Valen-/tina/uxsor/ Titini.h(ic)/sep(ulta).est/an(norum) XXXI.

Debajo del epígrafe hay un toro ${ }^{73}$.

13. A. Tovar ${ }^{74}$, al estudiar las lenguas y los pueblos de la Hispania Antigua, alude a la religión de los pueblos hispanos. Examina la inscripción de Cabeço das Fraguas, que es un suovetaurilia ${ }^{75}$. Menciona al dios Lug de Peñalba de Villastar ${ }^{76}$, y al mito de Habis ${ }^{77}$.

14. M. Beltrán ${ }^{78}$ con motivo de describir la II Edad del Hierro en el Valle del Ebro recoge algunos datos sobre la religión de esta zona, como son: el monumento de Binéfar (La Vispesa), con representaciones de manos cortadas, y de caballos, de claro sentido funerario, con mención del dios Neitin, relacionado con Neto; recuerda a la diosa Obana de Celsa; al dios Sucellus de la Guardia de Alcorisa (Teruel); a la divinidad civilizadora arando, entre palomas, con una pareja de bueyes; a la Gran Diosa Madre de Oliete; a la terracota de Castillo de Alloza; al árbol de la vida de Azaila, y a los animales de carácter sacral de esta pintura; al lobo; a los thimiateria de Azaila, Oliete, etc. Estudia brevemente la religión de Celtiberia, la de los berones, y la de los vascones y pueblos vecinos, recordando a los principales dioses y el ritual funerario.

15. C. Blasco, al describir la España celtibérica ${ }^{79}$, examina los ritos

72 U. EsPinOSA, L. M. Usero, op. cit., pág. 485 y ss., n..$^{\circ}$ 13, Lám. 6.

${ }^{13}$ U. ESPINOSA, L. M. UsERo, op. cit., pág. 487, n. ${ }^{\circ}$ 17, Lám. 8.

${ }^{74}$ Lenguas y pueblos de la Hispania Antigua. Lo que sabemos de nuestros antepasados protohistóricos, Vitoria, Gasteiz, 1985.

${ }_{75}$ A. TOVAR, op. cit. $12 \mathrm{~s}$.

${ }^{76}$ A. TOVAR, op. cit. 17.

7 A. TOVAR, op. cit. $28 \mathrm{~s}$.

78 "La España celtibérica: La segunda Edad del Hierro en el valle del Ebro", Historia general de España y América. De la protohistoria a la conquista romana, Madrid, 1987, 280 ss.

79 "La España celtibérica: la segunda Edad del Hierro en la Meseta", Historia general de España y América. De la protohistoria a la conquista romana, 320 ss. 


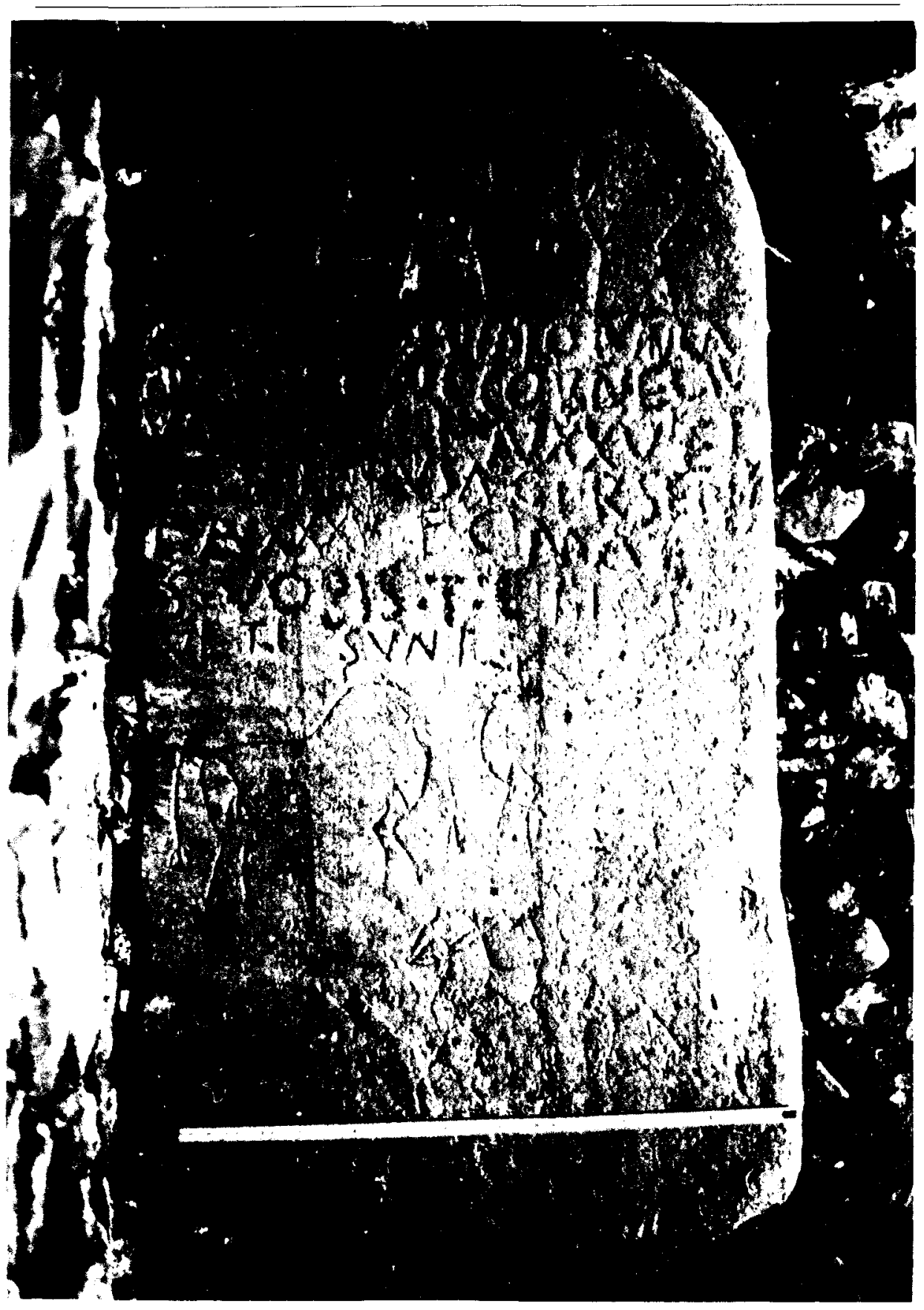

Fig. 17. Estela de Vizmanos. Soria. Cortesia de U. Espinosa. 
funerarios y las manifestaciones religiosas, como los verracos, el santuario del Cerrón en Illescas, Toledo; otros posibles santuarios a cielo abierto; los bóvidos de Numancia; las representaciones solares de esta ciudad; los ritos relacionados con el fuego; los thimiateria y las deidades de carácter infernal, etc.

16. C. Fernández Ochoa ${ }^{80}$, al tratar los pueblos lusitanos y celtíberos, dedica unas páginas a las creencias y mitos, fijándose en los principales dioses, como Arentia, Endovellico, la inscripción de Cabeço das Fraguas, Ataecina, los compuestos de Band-; y en el ritual funerario.

La misma autora ${ }^{81}$ dedica también especial interés a las creencias y mitos de los pueblos del norte de España: a los dioses compuestos de Coso-, a Marte, a los compuestos de Band-, a Nabia, a la luna, etc.

17. Ana Vázquez ${ }^{82}$ ha dedicado unas páginas a la pervivencia de los cultos indígenas en la Hispania romana, pasando revista a las principales fuentes literarias y epigráficas, a las causas de la pervivencia de los cultos indígenas, como a la tolerancia y a la interpretatio romana de estos cultos. Menciona algunos teónimos indígenas, como Baelesto, Peremusta, Aituneo, las Matres Useae, Cernunnos de Numantia, Endovellico y Ataecina, Sucellus, Epona, Bormanico, Tullonio y Frovida, al balneario de Retortillo con las Aquae Eleteses, al balneario de Montemayor, Cáceres, la Nabia Corona de Marecos, y a otros dioses del panteón indígena. Alude Ana Vázquez a la cristianización de los dioses indígenas. Cierra este apartado la autora con unos párrafos consagrados a los dedicantes. Piensa Ana Vázquez que algunos dioses indígenas tenian carácter nacional, como Endovellico, las Matres Gallaicae, la Tuleta Bolgensis. Otros dioses son de gentilidad, como Pomona o Tullonio. Algunos dioses van vinculados con una ciudad, como Ataecina Turobrigense. Predominan las dedicatorias ofrecidas por ciudadanos particulares. A veces los dedicantes son extranjeros.

${ }^{80}$ "Los pueblos prerromanos de la fachada atlántica: lusitanos y célticos", Historia general de España y América. Desde la protohistoria a la conquista romana, 350 ss.

${ }^{81}$ C. FeRnÁNDEZ OCHOA, "La cultura castreña de los pueblos del norte y noroeste en la segunda Edad del Hierro", Historia general de España y América. Desde la protohistoria a la conquista romana, 375 ss.

${ }^{82}$ "La crisis" y el Bajo Imperio: La religiosidad en la España Romana", Historia General de España y América, II, Madrid, 1987, 427 ss. 
18. M. L. Albertos ${ }^{83}$ publica las aras consagradas a Loxa, a Arentius y a Duilis, con fotos de las tres, y las inscripciones de Peñalba de Villastar y de Cabeço das Fraguas con dibujos.

83 "Lenguas primitivas de la Península Ibérica", Boletín de la Institución "Sancho el Sabio», 17, 1973, passim. 